\title{
TASK ANALYSIS ON MAINTENANCE WORKER (RAIL GRINDER) OF LIGHT RAIL TRANSIT (LRT)
}

\author{
Jacquelyne AB, Azlis-Sani J, Nor Azali A, Nur-Annuar M, Shahrul Azhar S and Mifzal-Nazhan M \\ Faculty of Mechanical and Manufacturing Engineering, Universiti Tun Hussein Onn Malaysia, 86400 Batu Pahat, Johor, \\ Malaysia. \\ Safety, Health and Environment Department, Rapid Rail Sdn Bhd, No 1, Jalan PJU 1A/46, Off Jalan Lapangan Terbang \\ Subang, 47301 Petaling Jaya Selangor, Malaysia.
}

* Corresponding author: Azlis-Sani J

Email: azlis@uthm.edu.my

\begin{abstract}
Rail maintenance routines are necessary to enable the all rail operations to achieve its aim in maintaining a safe and efficient operation. The maintenance tasks expose the workers to vibration and noise, as they handle specialized machineries and heavy self-propelled vehicles. Exposure of noise above the permissible exposure limit and over the daily allowable duration may cause noise-induce hearing loss (NIHL). Investigation on the type of task that has high noise level exposure on the maintenance workers was conducted to justify the needs to further detailed of this study. This paper will describe the task analysis on maintenance workers and to identify possible tasks with exposure to high level of noise. It scopes down to grinding crew of the maintenance department of light rail transit. Methods used were real-time sound measurement using a sound level meter, observation and interviews. Then, data were analysed to understand the situation of exposure of noise during rail maintenance. An ergonomic risk assessment was also conducted by adoption of the latest guideline on Ergonomic Risk Assessment (ERA) at Workplace Guidelines recommended by Department of Occupational Safety and Health (DOSH), Malaysia. A hierarchical task analysis (HTA) was generated on the task of the maintenance worker, focusing on rail grinding crew. The newly generated HTA had allowed better understanding about the nature of work and the task conducted by a rail grinder during the work shifts. Tasks involving high noise level was identified. Data recorded shows that the noise level for the blowing activity was relatively high and exceeded the permissible exposure limit of 90dBA. The exposure level was currently controlled by practicing the usage of hearing protection equipment (HPE) and by controlling exposure time in accordance to recommendations of the Factory and Machinery Act (FMA). Thus, it had confirmed that maintenance workers were exposed to high noise levels when performing their daily task. Further studies are needed to investigate the relationship between the duration of exposure and noise-induce hearing loss (NIHL) with consideration of the lifestyles of the maintenance workers.
\end{abstract}

Keywords: Noise-induced hearing loss (NIHL), maintenance worker, occupational noise, hierarchical task analysis (HTA), ergonomics, railway.

\section{INTRODUCTION}

Transforming cities like Kuala Lumpur and the Greater Kuala Lumpur towards achieving status as world class sustainable cities requires strategic planning in managing its public transport system. As Malaysia's public transport has been contributing to the country's socioeconomic development ever since the agricultural era till today ${ }^{1}$, public transport remains as reliable mean of transportation as it eases traffic congestion ${ }^{2}$. In the rail transportation system, maintenance possesses a significant standing in ensuring smooth operations and quality services hence, is a vital fragment that must be emphasized ${ }^{3}$. The maintenance routines should be handled meticulously with a well-planned manner to ensure the rail operation meets the expectation of its users and to contribute to the economic growth of Kuala Lumpur and The Greater Kuala Lumpur. Initiatives encompass improved connectivity, accessible, safe, sustainable and efficient in its service and quality should be planned and taken to ensure continuous development of the public transport system. With maintenance rated as a highly important fraction of rail operation ${ }^{4}$, maintenance workers are to be responsible for the quality of routine involved. The maintenance tasks made them being exposed to vibration and noise, as they are to handle specialized machineries and heavy self-propelled vehicles. In a study conducted by Johanning $(2011)^{5}$, vibration and noise are obvious elements that will affect maintenance workers in whole. The nature of the maintenance work involves machines that may cause the maintenance environment to be uncomfortable and inappropriate for the task as maintenance tasks not only involves skills but also focus at a point of time; when on-duty. This may result to inefficiency, fatigue, injuries, accidents and behavioural changes of workers.

This paper aims to report the results of task analysis on maintenance workers, identify possible task with exposure to high level of noise, conduct ergonomics task analysis to identify noise exposure and provide 
recommendations based on problems and task analysis generated on maintenance workers.

\section{Noise Exposure \& Task}

\section{Hierarchical Task Analysis}

Encompasses a wide variety of techniques and methods in analysing task, task analysis is applicable in numerous settings and used diversely such as staffing, job organization, and training. It is most commonly found in the applied fields of human factors and industrial/organizational psychology ${ }^{6}$. There are many types of task analysis while one specific type is known as Hierarchical Task Analysis. This type of analysis was introduced through the efforts of Annett and Duncan (1967), to acknowledge greater cognitive understanding of a wide range of task $^{8}$. HTA analyses task by probing the hierarchy of goals and establishing plans to decide when and how subordinate goals should be accomplished. There are three governing principles of HTA set by Annett, Duncan, Stammers, and Gray (1971) which are:

i. Task at highest level is chosen as it consisted of an operation and the operation is defined in terms of its goal. The goal implies the objective of the system in some real terms of production units, quality or other criteria.

ii. The operation can be broken down into sub operations each defined by a sub goal again measured in real terms by its contribution to overall system output or goal, and therefore measurable in terms of performance standards and criteria.

iii. The important relationship between operations and sub-operations is really one of inclusion; it is a hierarchical relationship. Although tasks are often procedurals, that is the sub-goals have to be attained in a sequence, this is by no means always the case ${ }^{7}$.

Thus, the HTA framework provide sequences or structure to the task analysis and allows necessary details for each task. Task analysis methods are also used for the training of tasks and its application has become invaluable to the work place ${ }^{8}$.

\section{Noise-induced hearing loss}

In a study conducted in 2015 with reference to the medical records kept by the Norwegian State Railways (NSB), the train and track maintenance workers constitute was the largest group in the study and has higher noise exposure with and more hearing loss in the noise sensitive area (3-6 $\mathrm{kHz})^{9}$. The occupational noise exposure record for that constitute was 75-90+peak dBA, where $90 \mathrm{dBA}$ is the maximum permissible exposure limit.

In Malaysia, the existing Factories and Machinery (Noise Exposure) Regulations 1989 in their present form cover mostly only industries involved in manufacturing, construction, mining and quarrying. These guidelines have been drawn up to cater to the noise control needs of all occupations falling within the purview of the Occupational Safety and Health Act 1994. The statistics for cases of occupational noise induced hearing loss (NIHL) in Malaysia was reported to by Society Security Organization (SOCSO) in 1995-200910. With the established guidelines, in the long term it is hoped that a significant reduction in the incidence and severity of occupational noise induced hearing loss (NIHL) in all occupations through the application of noise control principles.

\section{METHODOLOGY}

\section{Ergonomic Risk Assessment}

A Guideline on Ergonomics Risk Assessment at Workplace has been published by the Department of Safety and Health (DOSH) Malaysia in 2017. This guideline aims to provide a systematic plan and an objective approach in identifying, assessing and controlling ergonomics risk factors associated with the work task and activities in the workplace. Through this guideline, an Ergonomic Risk Assessment (ERA) framework was introduced. The assessment depends on the types of ergonomics factors being identified. For analysis of environmental risk factors in work area evaluation methods that will be used includes an interview, observation and measurement using equipment for a real time assessment.

\section{Hierarchical Task Analysis}

Observation is used to gather data regarding activity conducted in complex, dynamic system. In the simplest form, it involves observing an individual or a group of individuals performing a work-related activity. The output from observational analysis is used as primary input for most human factor techniques such as task analysis, error analysis and charting techniques. In this study, the main objective in using observation was to observe the routine and activities performed by the maintenance workers to conduct the task analysis assessment. Through observation, the tasks being carried out by the maintenance workers can be identified and then recorded. 


\section{Exposure of Noise}

As stated in the Factories and Machinery (Noise Exposure) Regulations 1989, under Part VI Audiometric Testing Program, Regulation No. 26, the audiometric measuring instrument shall be of an approved type and shall be calibrated and maintained at regular intervals (Federal Subsidiary Legislation, 1989). As far as practicable, this research uses a sound analyser model that complies to the standard of IEC 60651 type2, 60804 type 2, ANSI S1.4 type2, and IEC 1260 (1995).

\section{RESULTS}

\section{Ergonomic Risk Assessment}

During the initial discussions with the Safety and Health Department as well as the Maintenance
Department of the collaborating company, the discussion session had acknowledged one of the items listed on the initial level of ERA checklist which was being exposed to annoying or excessive noise during working hours. On the other hand, according to the most recent third party report on the noise surveillance for rail grinders, it has noted that the activity does involve noise exposure above the Permissible Exposure Limit (PEL).

With reference to the Guidelines on Ergonomics Risk Assessment by DOSH, a 'YES' of 1 and above will initiate an advance assessment recommended the Guideline on Ergonomic Risk Assessment at Workplace by DOSH as listed in table 1. Hence, the discussion and third party report had both earned a 'YES' from the initial ERA stage and leads to the advance assessment stage.

Table 1: Initial ERA Criteria

\begin{tabular}{cc}
\hline Physical Risk Factor & \multicolumn{1}{c}{ Please Tick } \\
\cline { 2 - 2 } Noise exposure above Permissible Exposure Limit (PEL) & Yes \\
(Based on previous reports or measurement) & $\checkmark$ \\
Exposed to annoying or excessive noise during working hours & $\checkmark$ \\
\hline
\end{tabular}

\section{Hierarchical Task Analysis}

The development of Hierarchical Task Analysis was made possible through interview sessions and observation on the daily routine of the rail grinding crews. The HTA generated was structured into detailed subordinate goals and plans were discussed with the rail grinding crews during the interview. A task description or also known as the detailed diagram reflects on the overall flow of the task analysis of maintenance workers. Task analysis can be a powerful tool to give insight in task execution and to identify potential improvements in human-machine interaction ${ }^{11}$. In this study, the task analysis is performed in three phases, which are based on an HTA task decomposition with four levels of detail: task level, subtask level, within subtask levels. All data to develop the task analysis was obtained through interview, observation and with reference to the On-Job-Training and Maintenance Checklist.

Based on data collections, interviews, maintenance checklist and on-job training sheet obtained, the Hierarchical Task Analysis of Maintenance Workers (Rail Grinders) is generated as illustrated in figure 1. As listed in the figure, rail grinders work in three shifts to ensure the subsidiary tasks which are the preventive maintenance and rail grinding to be performed consistently. These are the main job scope of a rail grinder on the maintenance team. All these tasks will be subdivided into further detailed task analysis as shown in the following figures.

\section{Figure 1: Overall HTA of Maintenance Worker (Rail Grinder)}

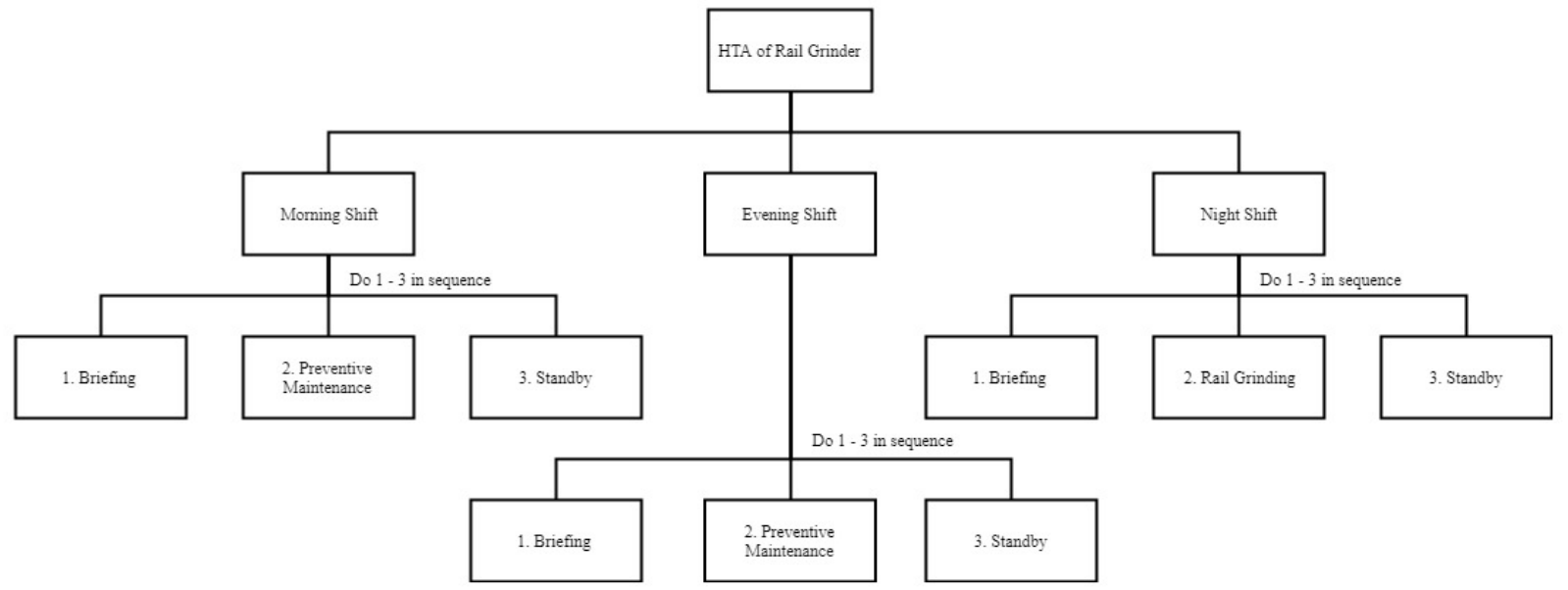


Figure 2: Overall HTA for Preventive Maintenance Activity)

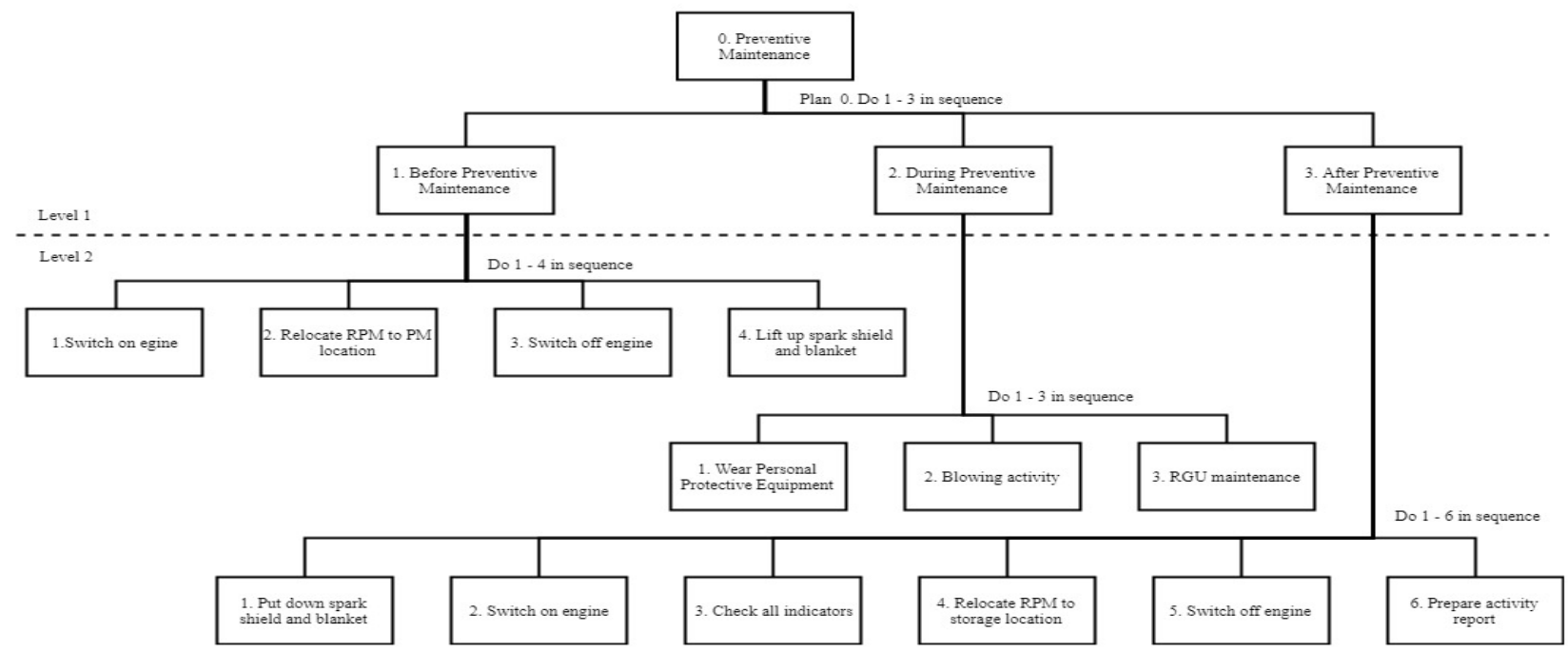

Figure 3: Overall HTA for Rail Grinding Activity

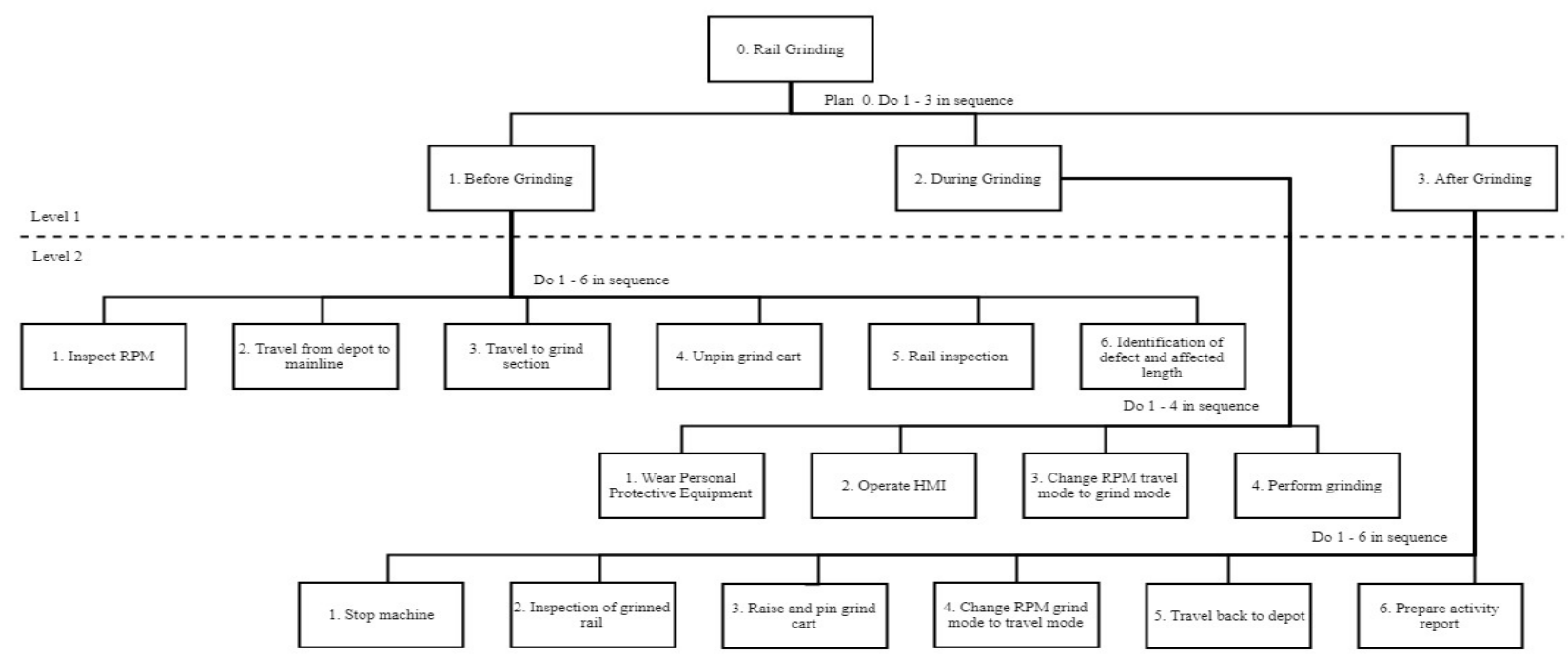

\section{Noise Exposure Analysis}

For all data shown in this subtopic, data 1 represents data collection 1, whereas data 2 represents data collection 2 . The activities being involved during data collection 1 and 2 are listed in table 2.

Table 2: Activities in Data Collection 1 \& 2

\begin{tabular}{|c|c|c|c|c|}
\hline \multirow[t]{2}{*}{ Activity } & \multirow[t]{2}{*}{ Description } & \multicolumn{2}{|c|}{ Activity Note } & \multirow{2}{*}{$\begin{array}{c}\text { Sampling } \\
\text { Duration (mins) }\end{array}$} \\
\hline & & $\begin{array}{l}\text { Data Collection } 1 \\
\text { (DT1) }\end{array}$ & $\begin{array}{l}\text { Data Collection } 2 \\
\text { (DT2) }\end{array}$ & \\
\hline A & RPM in Static Position at Depot & Non-Tunnel mainline & Non-Tunnel mainline & 3 \\
\hline $\mathrm{B}$ & RPM moving at $18-20 \mathrm{kph}$ & Non-Tunnel mainline & Non-Tunnel mainline & 3 \\
\hline $\mathrm{C}$ & $\begin{array}{l}\text { RPM moving at } 6-7 \mathrm{kph} \text { during } \\
\text { inspection }\end{array}$ & Non-Tunnel mainline & Tunnel mainline & 5 \\
\hline $\mathrm{D}$ & $\begin{array}{l}\text { RPM grinding on } 100 \text { amps } \\
\text { percentage }\end{array}$ & Non-Tunnel mainline & Tunnel mainline & 5 \\
\hline$E$ & $\begin{array}{l}\text { RPM grinding on } 80 \text { amps } \\
\text { percentage }\end{array}$ & Non-Tunnel mainline & Tunnel mainline & 5 \\
\hline $\mathrm{F}$ & $\begin{array}{l}\text { RPM grinding on } 50 \text { amps } \\
\text { percentage }\end{array}$ & Non-Tunnel mainline & Tunnel mainline & 5 \\
\hline G & $\begin{array}{c}\text { Preventive Maintenance - Blowing } \\
\text { Activity }\end{array}$ & Depot & Depot & Till work done \\
\hline
\end{tabular}


Activity A - F are done in a time frame of 12.00 midnight till 4.00 a.m. in the morning and activity $G$ is done in a time frame of 10.00 a.mm to 12.00 noon. The sound level meter was set-up facing the noise source for all of the activities and it is as illustrated in figure 4 and figure 5 .

Figure 4: Setup 1 of Sound Level Meter (SLM)

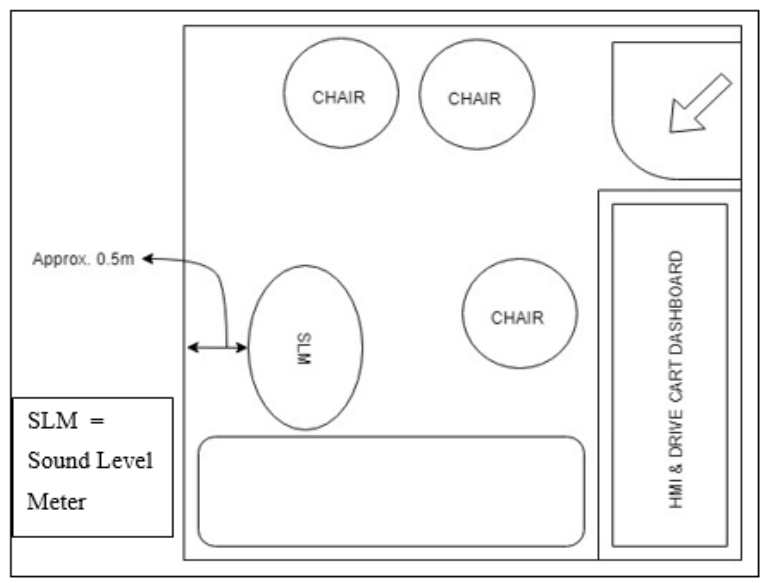

Compared to the readings of static, moving and grinding RPM which was taken in the RPM drive car, the reading of preventive maintenance was taken at an open-air location. No time sampling limit was set for this activity, thus the readings was taken from the beginning of the preventive maintenance blowing activity when the air compressor was switched on, till the end of the blowing activity, when the air compressor was switched off.

Figure 5: Setup 2 of Sound Level Meter (SLM)

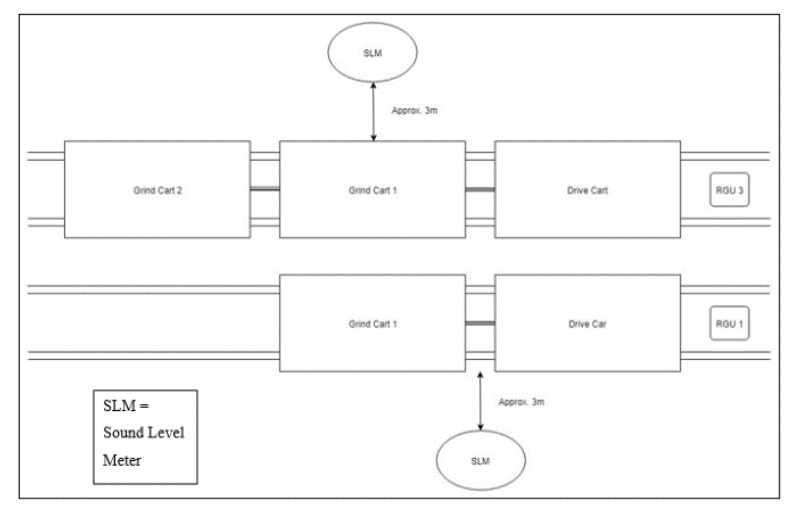

The distance of the sound level meter and the RPM at rest are approximately 3 meters apart as showed in figure 5. This was due to the unevenness of the ground and the limited space for movements of the maintenance crew in performing the blowing activity to remove the dust and particulates dissipated on the surface of RPM.

\section{DISCUSSION}

\section{Ergonomic Risk Assessment}

The Guideline on Ergonomic Workplace Assessment by DOSH Malaysia had suggested assessment methods for the advance assessment of ERA. For environmental risk factor, it had suggested to use methods that complies to the applicable Regulations, Industrial Code of Practice Standards and Guidelines, as well as to use designated specific measurement instruments. In this research, the suggested assessment methods were applied as far as practicable.

As stated in the Factories and Machinery (Noise Exposure) Regulations 1989, under Part VI Audiometric Testing Program, Regulation No. 26, the audiometric measuring instrument shall be of an approved type and shall be calibrated and maintained at regular intervals (Federal Subsidiary Legislation, 1989). As far as practicable, this research uses a sound analyzer model that complies to the standard of IEC 60651 type2, 60804 type 2, ANSI S1.4 type2, and IEC 1260 (1995). The guideline being referred for suggestion of basic noise control is the Guideline for Control on Occupational Noise 2005, which will be quoted later in the next chapter.

As to comply with the Ergonomic Risk Assessment (ERA) framework recommended by the Department of Safety and Health (DOSH), reporting and communication of risk to stakeholders are of some of the important elements in the ERA. On 30th May 2018, a presentation was conducted at the collaborator's office. The purpose of the presentation was to communicate the findings from the research to the Safety and Health Department and the Maintenance Department personnel. A technical report was submitted as reference to the assessments and findings of this research.

\section{Overall Noise Exposure at Work}

Overall, the average noise level for all activities measured are listed in table 3. Among Data 1 and Data 2, the highest average record goes to the preventive maintenance activity which involves the usage of compressed air to remove dust and particulates from the RPM or also known as the blowing activity. 
Table 3: Average Noise Level

\begin{tabular}{cccc}
\hline Activity & Description & \multicolumn{2}{c}{$\begin{array}{c}\text { Average Noise } \\
\text { (dBA) }\end{array}$} \\
& & (DT1) & (DT2) \\
\hline A & RPM in Static Position at Depot & 82.9 & 80.7 \\
B & RPM moving at 18 - 20 kph & 82.9 & 85.5 \\
C & RPM moving at 6-7 kph during inspection & 80.8 & 81.8 \\
D & RPM grinding on 100 amps percentage & 79.2 & 83.5 \\
E & RPM grinding on 80 amps percentage & 78.3 & 84.0 \\
F & RPM grinding on 50 amps percentage & 79.2 & 83.4
\end{tabular}

It is also significant that activities done in tunnel has higher average noise level as compared to the ones of non-tunnel activity. The non-tunnel activities don't differ much between data 1 and data 2. All the activities do not involve 8 hours of continuous exposure and majority of it does not exceed 90dBA except the preventive maintenance activity. Despite not exceeding the permissible exposure limit, the maintenance crews are still at risk due to the occupational noise and may have hearing impairments. Longterm, 3-5 years of exposure to noise level above $80 \mathrm{dBA}$ may eventually cause noise induced hearing loss $(\mathrm{NIHL})^{12}$. In another study, speech recognition scores were poor for individuals who were exposed to occupational noise of more than $80 \mathrm{dBA}$ although clinically, these individuals were tested and the result shows that they have normal hearing ${ }^{13}$.

However, for the general activities, which was the static position of RPM at depot, when RPM is moving at $18-20 \mathrm{kph}$ and during preventive maintenance, data collected shows that there was exposure of noise which exceeded the permissible exposure level. For RPM when it was static at depot, when it was moving 18-20kph and during preventive maintenance, the sound level meter has captured highest instantaneous reading of $92.0 \mathrm{dBA}, 90.2 \mathrm{dBA}$ and $106.4 \mathrm{dBA}$ respectively. It is compulsory for us to obey the rules that has been stated in FMA, which is:

\section{Regulation No. 5 - Permissible Exposure Limit}

i) No employee shall be exposed to noise level exceeding equivalent continuous sound level of $90 \mathrm{~dB}(\mathrm{~A})$ or exceeding the limits specified in the First Schedule or exceeding the daily noise dose of unity.

ii) No employee shall be exposed to noise level exceeding $115 \mathrm{~dB}(\mathrm{~A})$ at any time.
Regulation No. 6 - Impulsive Noise

i) No employee shall be exposed to impulsive noise exceeding a peak sound pressure level of $140 \mathrm{~dB}(\mathrm{~A})$

In reality, the distance between the sound level meter and the source should be kept as close as possible to reflect on the exposure of occupational noise on the maintenance crew. Due to the conditions on site and the type of instrument used which may hinder the maintenance crew's task, the sound level meter was placed at approximately 3 meters away from the RPM. The relationship between the sound pressure level and the sound power level can be determined by the following equation ${ }^{14}$ :

$$
S P L=L W-20 \log r-11
$$

Where,

$$
\begin{aligned}
\mathrm{SPL} \quad= & \text { Sound Pressure Level, sound at a } \\
& \text { distance, } r . \\
\mathrm{LW} \quad= & \text { Sound Power Level, sound at the } \\
& \text { source. } \\
\mathrm{R} \quad= & \text { Distance between the source and the } \\
& \text { sound level meter }
\end{aligned}
$$

Hence, from the consideration of such relationship, the approximated noise exposure on the maintenance crew are as tabulated in the table 4.

According to the data that has been obtained, the noise exposure exceeded the permissible limit of $115 \mathrm{dBA}$ at any time but has not exceed the impulsive noise level of $140 \mathrm{dBA}$. The noise level recorded also exceeded the permissible exposure limit of $90 \mathrm{dBA}$. Thus, it is necessary for us to implement any kind of solution that could reduce the noise exposure among the workers. 
Table 4: Approximated noise exposure on the maintenance crew

\begin{tabular}{cccc}
\hline Activity & Description & Corrected Noise Exposure (dBA) \\
& & DT1 & DT2 \\
\hline$G$ & Preventive Maintenance - Blowing Activity & 116.1 & 116.0 \\
\hline
\end{tabular}

On the other hand, the management had put effort in ensuring the risks of workers' exposure towards high noise level were in control. The management has been ensuring that workers perform the blowing activity within the allowable time limit as per recommended in the FMA. Hence, this practice should be continued for the better of the workers.

\section{Noise Exposure Reduction}

The last level within the hierarchy is wearing personal protective equipment (PPE). This is the "last line of defence" if the earlier level of hierarchy is not practical or could not be applied. Workers should wear ear plug or ear muff all the time while working during the blowing activity. To minimise the noise level exposure from $115 \mathrm{dBA}$ to below $80 \mathrm{dBA}$ to reduce the risk of noise induced hearing loss (NIHL).

In order to achieve noise level of below $80 \mathrm{dBA}$ by the receiver, it is best that both ear plugs, and ear muffs are to be worn during performing the blowing activity. When either using earmuffs and earplugs, workers are to be equipped with earmuffs and earplugs at least NRR = 37 and NRR $=33$ respectively to lower the noise exposure to $80 \mathrm{dBA}$. Using either one of earmuff or earplug does not reduce much noise received by the worker, hence the usage of both earplugs and earmuffs are highly recommended.

\section{CONCLUSION}

Hierarchical Task Analysis (HTA) developed shown that the main tasks of maintenance worker (rail grinder) are rail grinding and to perform preventive maintenance. Both of these tasks can be broken down into three subsidiary parts of task which are before, during and after of the main tasks. Each subsidiary task can then be branched out into more sequential task which eventually made up an overall hierarchical task analysis of four levels.

Based on interviews and observations conducted during the case study, both respondents and sound analysis data confirms that there is involvement of high noise exposure when performing the task of a maintenance worker, in this context, the rail grinders. Overall, all of the tasks involve low frequency noise except for preventive maintenance during which uses compressed air to remove dust and particulate from the RPM or also known as the blowing activity.

The average sound level was calculated, and the results show that there only the preventive maintenance activity involves sound higher than the permissible exposure level as allowed and stated in the Factories and Machinery (Noise Exposure) Regulations 1989 under the Factories and Machinery Act 1967 (Act 137).

\section{ACKNOWLEDGEMENTS}

The authors were supported by the Fundamental Research Grant Scheme (FRGS) Vot 1542 Ministry of Higher Education Malaysia; managed by Research Management Centre (RMC) Universiti Tun Hussein Onn Malaysia. The authors would also like to thank Rapid Rail Sdn Bhd and Prasarana Malaysia Berhad on the contribution and participation for this study.

\section{REFERENCES}

1. Aziz, A. A. (2014). Malaysia's 2030 Agenda Accessible and Sustainable Public Transport, 41.

2. Mohamad, H. (2003). Rail Transportation in Kuala Lumpur. Japan Railway and Transport Review, 35(July), 21-27.

3. Farrington-Darby, T., Pickup, L., \& Wilson, J. R. (2005). Safety culture in railway maintenance. Safety Science, 43(1), 39-60.

4. Lidén, T. (2015). Railway infrastructure maintenance - A survey of planning problems and conducted research. Transportation Research Procedia, 10(July), 574-583.

5. Johanning, E. (2011). Vibration and shock exposure of maintenance-of-way vehicles in the railroad industry. Applied Ergonomics, 42(4), 555-562.

6. Kirwan, B., \& Ainsworth, L. K. (1992). A guide to task analysis: the task analysis working group. CRC press.

7. Salmon, P., Jenkins, D., Stanton, N., \& Walker, G. (2010). Hierarchical task analysis vs. cognitive work analysis: Comparison of theory, methodology and contribution to system design. 
Theoretical Issues in Ergonomics Science, 11(6), 504-531.

8. Felipe, S. K., Adams, A. E., Rogers, W. A., \& Fisk, A. D. (2010). Training novices on hierarchical task analysis. Human Factors, 2005-2009.

9. Lie, A., Skogstad, M., Johnsen, T. S., Engdahl, B., \& Tambs, K. (2015). The Prevalence of Notched Audiograms in a Cross-Sectional Study of 12,055 Railway Workers. Ear and Hearing, 36(3), e86e92.

10. Social Security Organization. (2009).

Statistik Kes Hilang Pendengaran Akibat Bunyi Bising 1995-2009. Retrieved December 6, 2017, from http://www.dosh.gov.my/index.php?opti on=com_docman\&task=doc_download\&gi $d=329$ \& $\mid$ temid $=496$

11. Boessenkool, H., Wildenbeest, J. G. W., Heemskerk, C. J. M., de Baar, M. R., Steinbuch, M., \& Abbink, D. A. (2017). A task analysis approach to quantify bottlenecks in task completion time of telemanipulated maintenance. Fusion Engineering and Design, 129 (March 2017), 300-308.

12. Jaafar, N. I., Md Daud, M. K., Mohammad, I., \& Abd Rahman, N. (2017). Noise-induced hearing loss in grass-trimming workers. Egyptian Journal of Ear, Nose, Throat and Allied Sciences, 18(3), 227-229.

13. Eggermont, J. J. (2017). Effects of longterm non-traumatic noise exposure on the adult central auditory system. Hearing problems without hearing loss. Hearing Research, 352, 12-22.

14. Smith, B. J., Peters, R. J., \& Owen, S. (1996). Acoustics and noise control (Second). London, United Kingdom: Pearson Education, Inc. 